\title{
Updating Predictive Models for Vertical Swell Percentage of Expansive Clays
}

\author{
Moshe Livneh \\ Faculty of Civil and Environmental Engineering, Technion-Israel Institute of Technology, Israel
}

\begin{abstract}
Since the publication of the Israeli swelling model in 2011, new swelling test results have become available (all together on 897 undisturbed clay specimens), enabling an updating of the existing swelling model. Thus, it is logical to update this existing model to obtain a more accurate prediction of vertical swelling under a given vertical pressure exerted on the clay under consideration. This paper concentrates on the required updating, together with (a) a search for modified independent variables for the model equations and (b) a division of the 897 undisturbed specimens into two separate groups, one for the A-4 and A-6 material and the second for the A-7-5 and A-7-6 material, in order to enhance the accuracy of vertical swelling prediction. The final recommendation is to use two swelling models (the general one for the A-7-5 and A-7-6 material and the specific one for the A-4 and A-6 material), based on modified independent variables listed in the paper.
\end{abstract}

Keywords: Vertical swelling percentage, Swelling pressure, Heave, Expansive clay, Swelling model.

\section{INTRODUCTION}

Predicting the surface heave of pavements or railway-beds based on expansive clays is aided by a swelling model that reflects the relationship between the predicted vertical swell and the vertical surcharge acting on the clay at a given depth. The development of this model is shown by the author in [1] and [2].

To recall, the swelling model is obtained from laboratory tests on undisturbed clay specimens. The curves of this model are dependent on knowledge of the following parameters that characterize the clay being studied: (a) liquid limit, (b) the ratio between in-situ moisture content and plasticity limit, and (c) in-situ dry density.

The existing swelling model in Israel (from 2011) is based on swelling tests that were performed on 352 undisturbed specimens taken from a swelling clay stratum at several sites in Israel. The majority of these swelling tests were conducted according to ASTM 4546 Method B (for the vertical swelling percentage), and the remainder conducted according to ASTM 4546 Method C (for the swelling pressure).

Since the publication of the swelling model in [1] and [2], new test results have become available (all together on 897 undisturbed clay specimens), enabling an updating of the existing swelling model. Thus, it seems to be only logical to update this existing model in order to obtain a more accurate prediction of vertical swelling under a given vertical pressure exerted on the clay under consideration. To sum up, this paper concentrates on the required updating, together with (a) a search for modified independent variables for the model equations and (b) a division of the total 897 undisturbed specimens into two separate groups, one for the A-4 and A- 6 material and the second for the A-7-5 and A-7-6 material, in order to enhance the accuracy of vertical swelling prediction.

\section{UPDATING THE SWELLING MODEL}

The existing swelling model published in [1] and [2] presents the statistical relationship between (a) the vertical swelling pressures ( $\mathrm{Po}$ ), defined as the vertical pressure (i.e., the vertical surcharge, $\mathrm{Pp}$ ) that causes a zero vertical rate and the following features that characterize the undisturbed clayey specimen: moisture content (W) in percentage, and dry density (D) in $\mathrm{kN} / \mathrm{m}^{3}$, and (b) the vertical swell rate (Sp) in percentage, as a function of the vertical pressure $(\mathrm{Pp})$ in $\mathrm{kPa}$ and the predicted vertical swelling pressure $(\mathrm{Po})$ in $\mathrm{kPa}$. On local swelling tests results collected over time from 352 undisturbed clayey specimens at different sites in the country, a direct determination was performed in [1] and [2] by using the Excel-Solver command. This determination led to the two following equations:

$$
\begin{aligned}
& \log (\mathrm{Po} / 98.07)=-3.256+1.540 \times \log (\mathrm{LL})-0.537 \times \mathrm{W} / \mathrm{PL}+ \\
&+0.738 \times(\mathrm{D} / 9.81)) \\
& \mathrm{Sp}=-1.872 \times(\mathrm{Po} / 98.07) \times \log (\mathrm{Pp} / \mathrm{Po})
\end{aligned}
$$

The $\mathrm{R}^{2}$ value obtained for these two equations is 0.387 , which is a low value, but of the same order of magnitude as that obtained for the multiple regression analysis performed on 514 specimens in Kansas: 0.35 [3]. Furthermore, the value of the standard error (SE) obtained for these two equations is $1.453 \%$, and the ratio of this value to the standard deviation of the measured vertical swell values (SE/SY) is 0.788 . The plasticity chart for the 352 specimens is given in Figure 1.

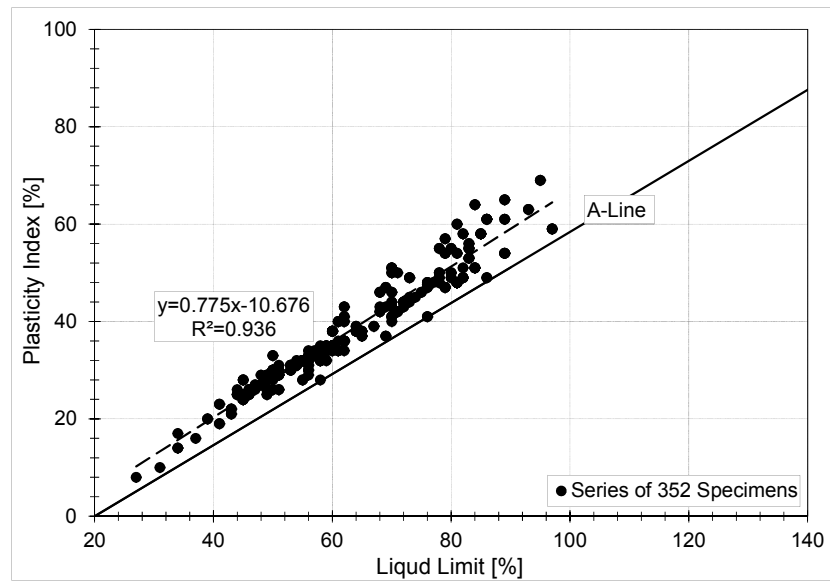

Figure 1: Plasticity index versus liquid limit of 352 undisturbed specimens utilized in (1) and (2)

Up to now, the sum of the previous 352 test results and the present 545 test results (i.e., all together 897 test results) which had become available for updating the swelling model with the Excel-Solver command led to two new 
equations:

$$
\begin{gathered}
\log (\mathrm{Po} / 98.07)=-4.234+2.110 \times \log (\mathrm{LL})-0.399 \times \mathrm{W} / \mathrm{PL}+ \\
+0.604 \times(\mathrm{D} / 9.81) \\
\mathrm{Sp}=-2.191 \times(\mathrm{Po} / 98.07) \times \log (\mathrm{Pp} / \mathrm{Po})
\end{gathered}
$$

The standard error (SE) associated with the development of these two equations is $1.952 \%$, and the coefficient of determination $\left(\mathrm{R}^{2}\right)$ obtained for them is higher than that associated with (1) and (2), 0.604. Finally, the ratio of the value of $\mathrm{SE}$ to the standard deviation of the measured vertical swelling values (SE/SY) is 0.631 , or lower than that associated with (1) and (2).

In addition to these statistic-values, Figure 2 summarizes the overall prediction accuracy of the swelling model given by (3) and (4). A measure of overall bias in this prediction model is reflected in how closely the unconstrained linear regression line of predicted versus measured vertical swelling matches the line of equality; i.e., how close are the unconstrained intercept and slope to 0 and 1, respectively.

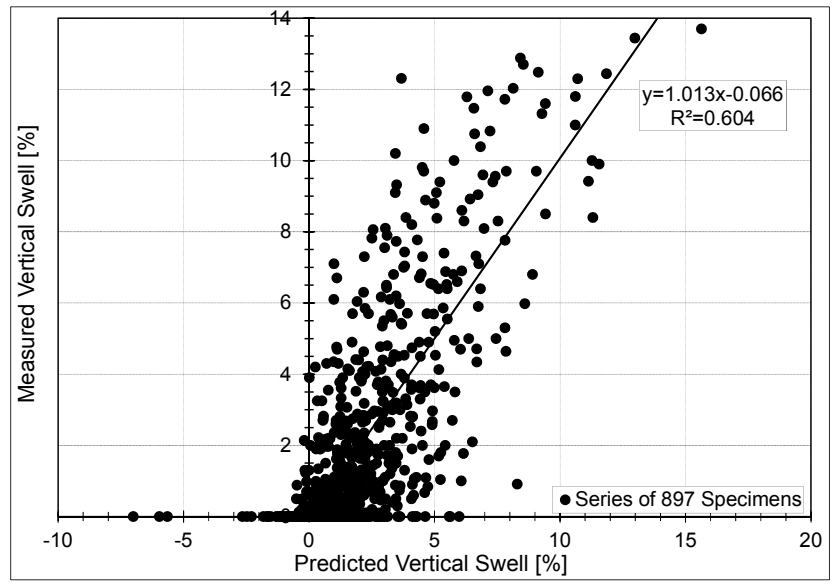

Figure 2: Predicted, from (3) and (4), versus measured vertical swelling of 897 undisturbed specimens

In this regard, Figure 2 indicates that practically, the unconstrained regression line has a zero intercept and a slope value of 1 , thus exhibiting a zero bias and, on the average, almost full similarity between measured and predicted values.

Finally, the plasticity chart for the 897 specimens is given in Figure 3. Comparing Figure 3 with Figure 1 leads to the conclusion that the additional 545 test results from undisturbed specimens do not change the plasticity characteristics of the clay.

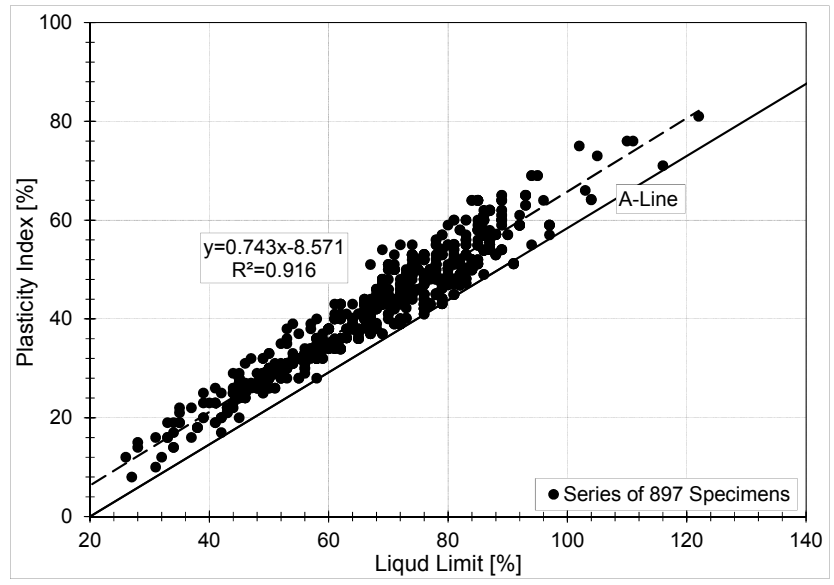

Figure 3: Plasticity index versus liquid limit of 897 undisturbed specimens utilized in (3) and (4)

\section{SEARCH FOR MODIFIED VARIABLES}

In order to enhance the accuracy of vertical swelling predictions, a search for modified independent variables was conducted, with the following independent variables suggested: (a) $\log (\mathrm{PI})$ instead of $\log (\mathrm{LL})$ and (b) $\mathrm{D} / 9.81 /(2.1-0 / 007 \times \mathrm{LL})$, termed in this paper DR, instead of $\mathrm{D} / 9.81$. The reason for replacing LL with PI (i.e., plasticity index instead of liquid limit) is that PI is the preferable variable in various studies, such as [3, 4, 11, 12, 14 and 15]. In addition, the reason for replacing $\mathrm{D} / 9.81$ with $\mathrm{D} /(2.1-0.007 \times \mathrm{LL})$ is that the state of natural compaction of the clay is not characterized by $\mathrm{D}$ itself, but by the ratio of the in-situ dry density to the maximum dry density obtained in the laboratory through modified Proctor compaction energy $\left(\mathrm{D}_{\mathrm{MP}}\right)$ as explained in [5]. According to [6], $\mathrm{D}_{\mathrm{MP}}$ is equal to the following expression:

$\mathrm{D}_{\mathrm{MP}}=(2.1-7 \times \mathrm{LL} / 1,000) \times 9.81$

where $\mathrm{D}$ is given in $\mathrm{kN} / \mathrm{m}^{3}$.

It should be added here that the logic behind the above replacement of D is the same as for the replacement of the original variable of $\mathrm{W}$ with W/PL. Again, the state of in-situ moisture is not characterized by $\mathrm{W}$ itself, but by the ratio of in-situ moisture content to the plasticity limit as shown in [6]. These replacements lead to the following equations:

$$
\begin{gathered}
\log (\mathrm{Po} / 98.07)=-2.805+1.482 \times \log (\mathrm{LL})-0.418 \times \mathrm{W} / \mathrm{PL}+ \\
+0.688 \times(\mathrm{DR}) \\
\mathrm{Sp}=-2.263 \times(\mathrm{Po} / 98.07) \times \log (\mathrm{Pp} / \mathrm{Po}) \\
\log (\mathrm{Po} / 98.07)=-1.896+1.261 \times \log (\mathrm{PI})-0.528 \times \mathrm{W} / \mathrm{PL}+ \\
+0.573 \times(\mathrm{DR}) \\
\mathrm{Sp}=-2.122 \times(\mathrm{Po} / 98.07) \times \log (\mathrm{Pp} / \mathrm{Po})
\end{gathered}
$$

where

$$
\mathrm{DR}=\mathrm{D} /(9.81 \times(2.1-0.007 \times \mathrm{LL})
$$

The standard error (SE) associated with (6) and (7) is $1.974 \%$, and the coefficient of determination $\left(\mathrm{R}^{2}\right)$ obtained for these two equations is 0.595 . Finally, the ratio of SE to the standard deviation of the measured vertical swelling values $(\mathrm{SE} / \mathrm{SY})$ is 0.638 .

In the same manner, the standard error (SE) value associated with (8) and (9) is $1.938 \%$, and the coefficient of determination $\left(\mathrm{R}^{2}\right)$ obtained for these two equations is 0.610 . Finally, the ratio of SE to the standard deviation of the measured vertical swelling values (SE/SY) is 0.626 . In addition to Figure 2, Figure 4 summarizes the overall prediction accuracy of the swelling model given by (8) and (9). The figure indicates that the unconstrained regression line has a zero intercept and a slope value of 1 , thus exhibiting a zero bias and, on the average, almost full similarity between measured and predicted values. In addition, the coefficient of determination $\left(\mathrm{R}^{2}\right)$ of the regression line of Figure 4 has a slightly higher value than that of Figure 2; i.e., 0.610 against 0.604 .

\section{DISCUSSION AND COMPARISON}

The preceding results indicate that the statistic values $\left(\mathrm{R}^{2}\right.$ and SE/SY) obtained for (8) and (9) are the most favorable 
of all these values.

Here, it is interesting to compare all the statistic-values given in the preceding sections with those in Table 1. This table contains the statistical criterion for goodness of fit (SE/SY) and validity of correlation $\left(\mathrm{R}^{2}\right)$ as taken from [7] for five states of correlation: excellent, good, fair, poor and very poor.

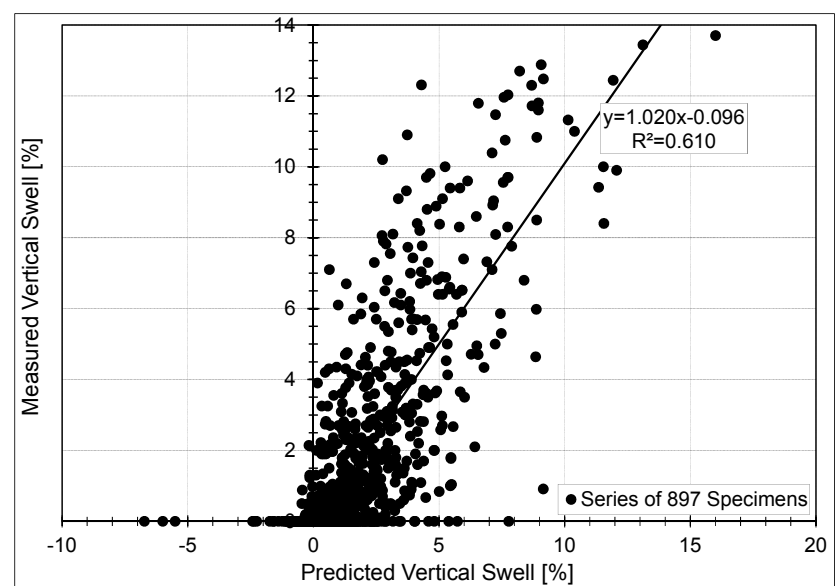

Figure 4: Predicted, from (8) and (9), versus measured vertical swelling of 897 undisturbed specimens

This comparison leads to the conclusion that the Excel Solver analysis on 897 specimens can be categorized as leading to a fair state of correlation for three sets of equations: (3) and (4), (6) and (7) and (8) and (9).

Table 1: Statistical criterion for goodness of fit statistic (SE/SY) and validity of correlation statistic $\left(\mathrm{R}^{2}\right)$, all taken from [7]

\begin{tabular}{ccc}
\hline Criteria for & $\mathrm{R}^{2}$ & $\mathrm{SE} / \mathrm{SY}$ \\
Correlation & $\geq 0.90$ & $\leq 0.35$ \\
\hline Excellent & $0.70-0.89$ & $0.36-0.55$ \\
Good & $0.40-0.69$ & $0.56-0.75$ \\
Fair & $0.20-0.39$ & $0.76-0.90$ \\
Poor & $\leq 0.19$ & $\geq 0.91$ \\
Very Poor &
\end{tabular}

Now, it is interesting to compare the predicted swelling curves according to the above three sets of equations. This is done in Figure 5 for the following cases of W/PL and D: (a) 0.8 and $14.7 \mathrm{kN} / \mathrm{m}^{3}$, (b) 1.0 and $14.7 \mathrm{kN} / \mathrm{m}^{3}$; and in Figure 6 for (a) 0.8 and $16.7 \mathrm{kN} / \mathrm{m}^{3}$, and (b) 1.0 and 16.7 $\mathrm{kN} / \mathrm{m}^{3}$.

Figure 5 indicates that the differences among the three solutions for the 897 undisturbed specimens are practically negligible. However, it may be also stated that the outputs of (8) and (9) yield the highest values for predicted vertical swelling. The same can be stated for Figure 6, except that the outputs of (8) and (9) do not always yield the highest values for this prediction.

Finally, it should be added that the statistic values obtained for the total 897 undisturbed specimens, and using the actual variables in the Excel Solver analysis (of the same type that led to the swelling equations (1) and (2)), are as shown in Table 2. In this table, the line of " $\log (\mathrm{LL}), \mathrm{W} / \mathrm{PL}$, D" corresponds to (3) and (4), the line of " $\log (\mathrm{LL}), \mathrm{W} / \mathrm{PL}$, DR" to (6) and (7) and the line of " $\log (\mathrm{PI}), \mathrm{W} / \mathrm{PL}, \mathrm{DR}$ " to (8) and (9). Here it should be noted that Table 2 also contains the statistic values for another three sets of independent variables as defined in the table.
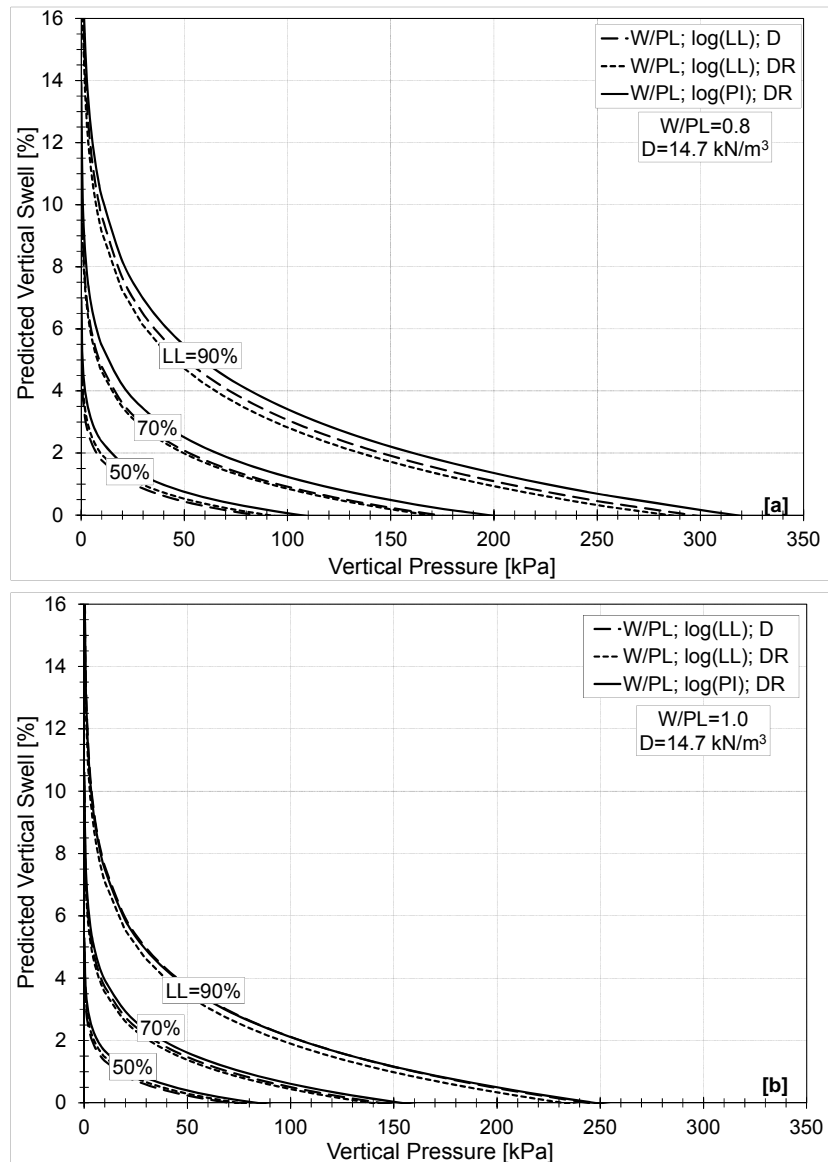

Figure 5: Predicted vertical swelling versus vertical pressure for $\mathrm{D}=14.7 \mathrm{kN} / \mathrm{m}^{3}$ and for (a) $\mathrm{W} / \mathrm{PL}=0.8$ and (b) $\mathrm{W} / \mathrm{PL}=1.0$
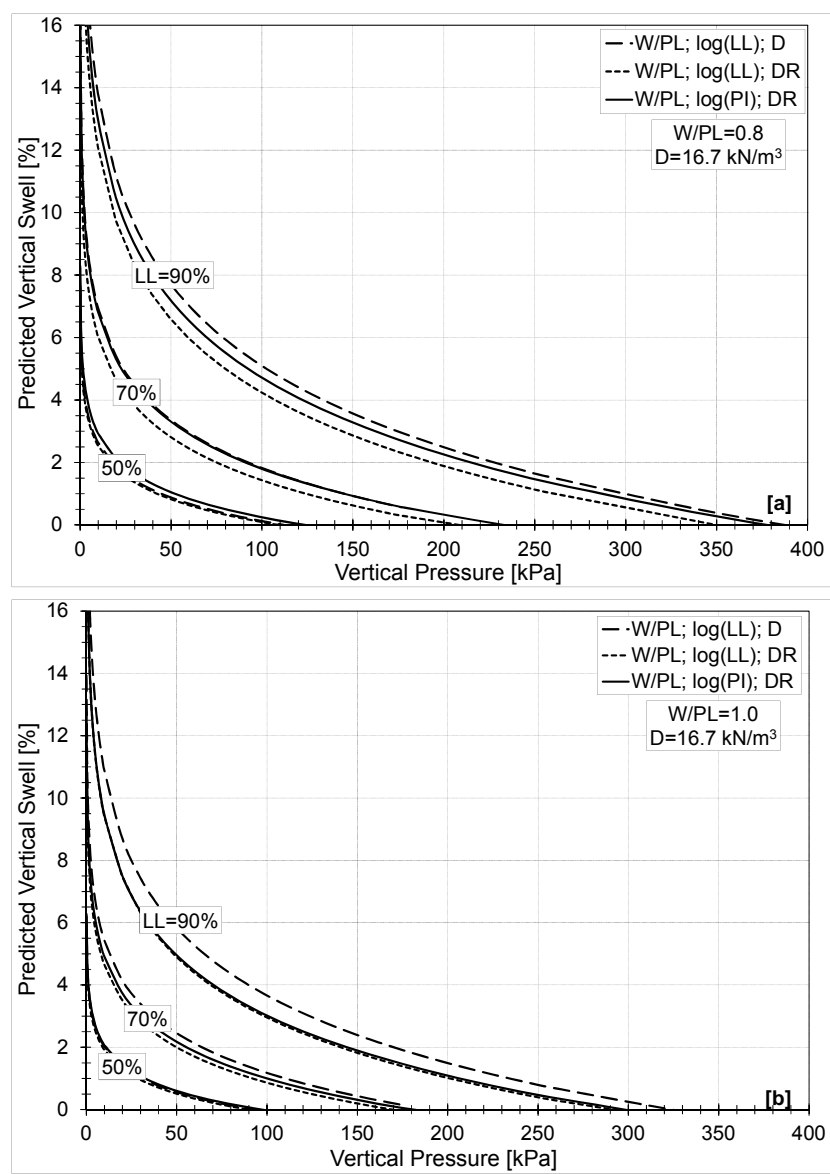

Figure 6: Predicted vertical swelling versus vertical pressure for $\mathrm{D}=16.7 \mathrm{kN} / \mathrm{m}^{3}$ and for (a) W/PL=0.8 and (b) $\mathrm{W} / \mathrm{PL}=1.0$ 
Table 2: Statistic values for the swelling model equations with the designated variables

\begin{tabular}{cccc}
\hline Variables & $\mathrm{R}^{2}$ & SE/SY & SE (\%) \\
\hline LL, W, D & 0.576 & 0.653 & 2.020 \\
$\log (\mathrm{LL}), \mathrm{W} / \mathrm{PL}, \mathrm{D}$ & 0.604 & 0.631 & 1.952 \\
$\log (\mathrm{LL}), \mathrm{W} / \mathrm{PL}, \mathrm{DR}$ & 0.595 & 0.638 & 1.974 \\
\hline PI, W, D & 0.457 & 0.738 & 2.284 \\
$\log (\mathrm{PI}), \mathrm{W} / \mathrm{PL}, \mathrm{D}$ & 0.587 & 0.664 & 1.992 \\
$\log (\mathrm{PI}), \mathrm{W} / \mathrm{PL}, \mathrm{DR}$ & 0.610 & 0.626 & 1.938 \\
\hline
\end{tabular}

Table 2 indicates that for the same experimental data, the statistics values improve with a change in the independent variables. For example, $\mathrm{R}^{2}$ improves from the low value of 0.457 to the high value of 0.610 when the independent variables change from "PI, W, D" to "log(PI), W/PL, DR."

\section{THE TWO GROUPS ANALYSIS}

Again, in order to enhance the accuracy of vertical swell prediction, the total 897 inputs was divided into two groups: (a) A-4 and A-6 material (i.e., silt and clay possessing $\mathrm{LL} \leq 40 \%$ ); (b) A-7-5 and A-7-6 material (i.e., silt and clay possessing $\mathrm{LL}>40 \%$ ).

The application of the Excel command to the data of these two groups leads to the following equations:

For the A-4 and A-6 materials:

$$
\begin{gathered}
\begin{array}{c}
\log (\mathrm{Po} / 98.07)=-20.440+11.538 \times \log (\mathrm{LL})-1.066 \times \mathrm{W} / \mathrm{PL}+ \\
+1.349 \times \mathrm{D}
\end{array} \\
\mathrm{Sp}=-8.838 \times(\mathrm{Po} / 98.07) \times \log (\mathrm{Pp} / \mathrm{Po}) \\
\log (\mathrm{Po} / 98.07)=-6.509+5.622 \times \log (\mathrm{PI})-1.319 \times \mathrm{W} / \mathrm{PL}- \\
-0.261 \times(\mathrm{DR})
\end{gathered}
$$

The values of the standard error (SE), the coefficient of determination $\left(\mathrm{R}^{2}\right)$ and the ratio of $\mathrm{SE}$ to the standard deviation of the measured vertical swelling values (SE/SY) associated with the above equations are shown in Table 3.

Table 3: Statistic values for the designated equations

\begin{tabular}{ccccc}
\hline Equations & $\mathrm{N}$ & $\mathrm{R}^{2}$ & $\mathrm{SE} / \mathrm{SY}$ & $\mathrm{SE} \mathrm{( \% )}$ \\
\hline (11) and (12) & 34 & 0.359 & 0.854 & 1.293 \\
$(13)$ and (14) & 863 & 0.605 & 0.630 & 1.969 \\
(3) and (4) & 897 & 0.604 & 0.631 & 1.952 \\
\hline (15) and (16) & 34 & 0.406 & 0.824 & 1.247 \\
(17) and (18) & 863 & 0.610 & 0.626 & 1.955 \\
$(8)$ and (9) & 897 & 0.610 & 0.627 & 1.938 \\
\hline
\end{tabular}

Figure 7 indicates that the predicted vertical swelling as calculated for the A-4 and A-6 material is much lower than that calculated for the total 897 specimens. The figure also shows that the predicted vertical swelling as calculated for the A-7-5 and A-7-6 material is practically identical with that calculated for the total 897 specimens. Differences in the general pattern, however, exist between Figure $7 \mathrm{a}$ Figure $7 b$, especially in the magnitude of the swelling pressure of the A-4 and A-6 materials. This result leads to the suggestion that the use of the $\log (\mathrm{PI})$ and $\mathrm{DR}$ variables is preferable from a safety factor point of view.
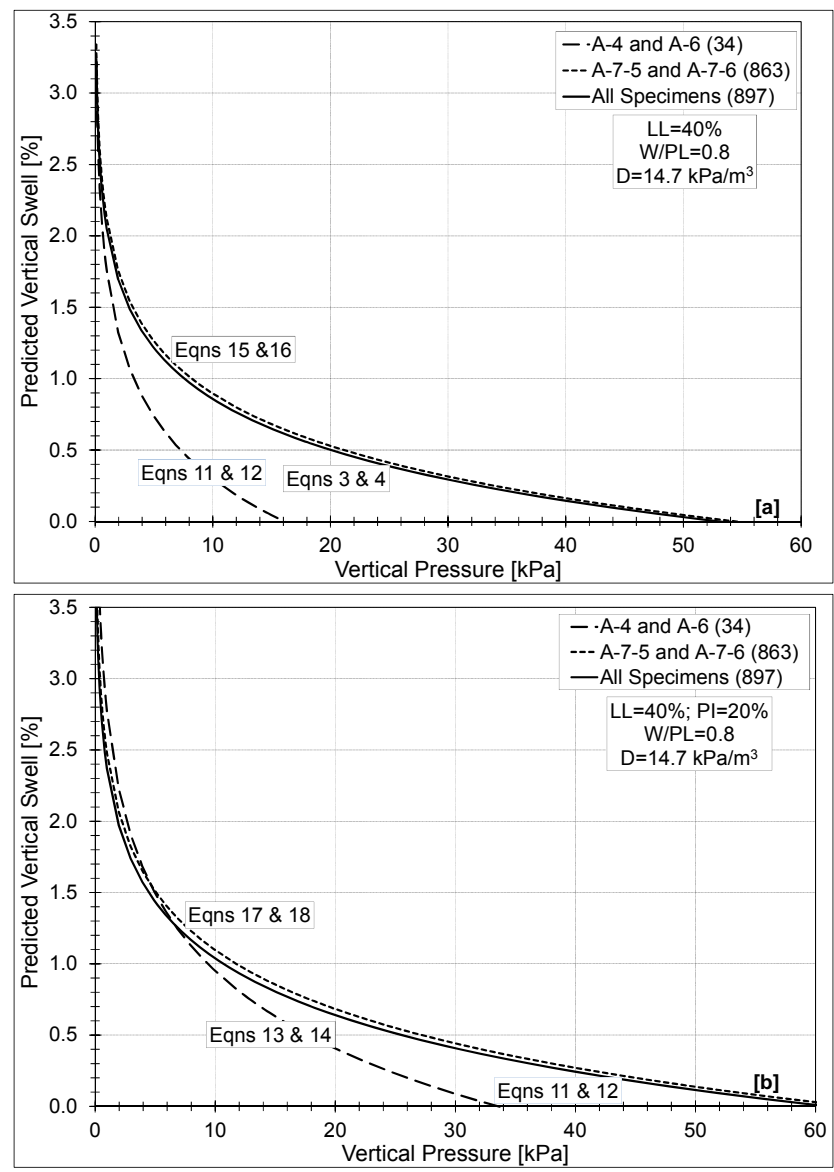

Figure 7: Predicted vertical swelling versus vertical pressure for $\mathrm{D}=14.7 \mathrm{kN} / \mathrm{m}^{3}, \mathrm{LL}=40 \%$ and $\mathrm{W} / \mathrm{PL}=0.8$ for the A-4 and A-6 material and for the A-7-5 and A-7-6 material according to (a) the $\log (\mathrm{LL}), \mathrm{W} / \mathrm{PL}$ and $\mathrm{D}$ variables and (b) the $\log (\mathrm{PI}), \mathrm{W} / \mathrm{PL}$ and DR variables

Here it should be noted that (15) and (16) lead, in contrast to what was expected, to decreased values of $\mathrm{Sp}$ with increasing values of DR. In other words, (15) yields a negative coefficient for the DR variable. This means that the practical use of (15) and (16) is questionable. Its use is doubtful, too, because of the low number of specimens (34) that went into obtaining the two equations in relation to the required number stemming from the given number of independent variables ( 5 in all). This last argument also applies to (11) and (12).

In light of the foregoing, it is suggested that the method given in [2] be applied. According to this reference, a specific equation for predicting the vertical swelling percentage that characterizes specific data (say, the specific values of liquid limit, plastic limit, the ratio of moisture content to plastic limit, dry density and the dry density ratio as defined by (10) of the given undisturbed specimens) is determined by combining (3) and (4) or (8) and (9) with the specific limited results of the laboratory swelling tests. These values and equations are combined by determining the regression coefficients $\alpha$ and $\beta$ of the linear regression carried out between the dependent variable $\mathrm{Sp}$ and the independent variable, the latter as specified in (4) or (8). In other words, the formulation of this linear regression 
equation is as follows:

$$
\mathrm{Sp}=\alpha+\beta \times[-2.191 \times(\mathrm{Po}) \times \log (\mathrm{Pp} / \mathrm{Po})]
$$

where, Po is calculated according to (3); $\alpha$ and $\beta$ are the linear regression coefficients,

or

$$
\mathrm{Sp}=\alpha+\beta \times[-2.122 \times(\mathrm{Po}) \times \log (\mathrm{Pp} / \mathrm{Po})]
$$

where, Po is calculated according to (8), $\alpha$ and $\beta$ are again the linear regression coefficients, as above.

In greater detail, the $\alpha$ coefficient of (19) or (20) is the intercept value with the Sp-axis (Y-axis), and the $\beta$ coefficient of (19) or (20) is the slope value with the Sp axis (X-axis) of (4) or (9). It should be noted that when $\alpha=0$ and $\beta=1$, (19) becomes identical with (4), or (20) becomes identical with as (9), which, as mentioned previously, constitutes the accepted general swelling model for heave calculations. In (19) or (20), the increase or decrease in swelling pressure (when $\alpha$ is positive or negative, respectively) is equal to the value of the swelling pressure obtained from the general swelling model (3) or (8), multiplied by the multiplier rate of 10 to the power of $[0.4564 \times \alpha /(\beta \times \mathrm{Po})]$ or $[0.4712 \times \alpha /(\beta \times \mathrm{Po})]$. In addition to the regression of (19) or (20) (known also as the simple linear regression), a supplementary regression is suggested, in which the prerequisite constraint of $\alpha=0$ exists. For this type of regression (known also as the zero-intercept regression, or regression through the origin), the $\beta$-coefficient serves as the multiplier for the increase or decrease in the general vertical swelling percentage. For this case, the multiplier rate for the swelling pressure is equal to 1 .

Figure 8 shows the suggested simple linear regression for both A-4 and A-6 material and A-7-5 and A-7-6 material, utilizing the general swelling model of (3) and (4). The values for the $\alpha$ and $\beta$ coefficients obtained in this figure are -0.096 and 0.607 (with $\mathrm{R}^{2}=0.166$ ), respectively, for the A-4 and A- 6 material, and -0.055 and 1.015 (with $\mathrm{R}^{2}=0.605$ ), respectively, for the A-7-5 and A-7-6 material. In a similar way, the values for the $\alpha$ and $\beta$ coefficients obtained for the general swelling model of (8) and (9) are -0.166 and 0.670 (with $\mathrm{R}^{2}=0.204$ ), respectively, for the A-4 and A-6 material, and -0.082 and 1.020 (with $\mathrm{R}^{2}=0.610$ ), respectively, for the A-7-5 and A-7-6 material. These latter values are similar to the previous ones.

Again, it can be seen from the above $\alpha$ and $\beta$ coefficients that the predicted vertical swelling for A-4 and A-6 material is much smaller than that based on the general swelling model of (3) and (4). As for the A-7-5 and A-7-6 material, the $\alpha$ and $\beta$ coefficients are practically identical. This can be seen, as well, in Figure 9 and Figure 10, plotted for the case of (a) the $\log (\mathrm{LL})$ and D independent variables and (b) the $\log (\mathrm{PI})$ and DR independent variables. A comparison of Figure 7 with Figures 9 and 10 yields some differences in outputs of vertical swelling and swelling pressure for the A-4 and A-6 material. For this group of material, the output of Figure 9 yields higher values than that of Figure 7, and the output of Figure 10 yields higher values than that of Figure 7 , for the case of $\log (\mathrm{LL})$ and D independent variables, and lower values than that of Figure 7 for the case of $\log (\mathrm{PI})$ and DR independent variables.

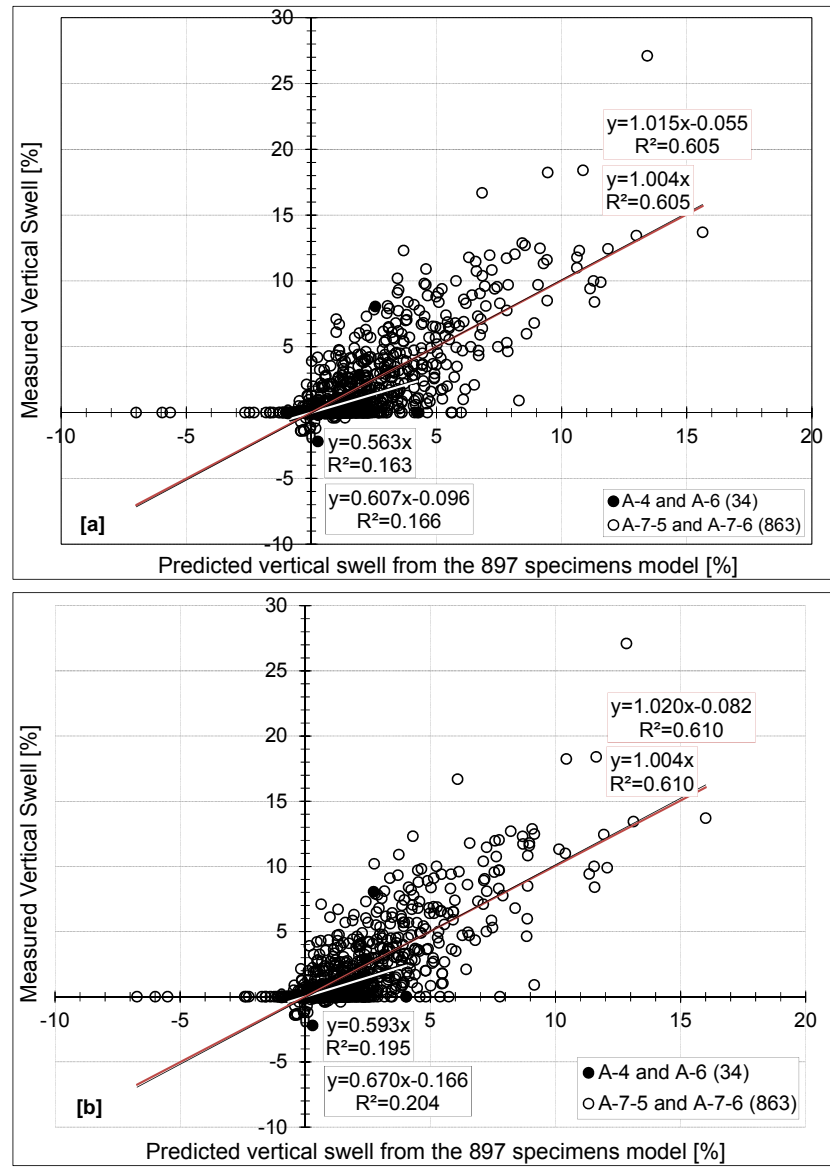

Figure 8: Derivation of $\alpha$ and $\beta$ coefficients for A-4 and A-6 material and for A-7-5 and A-7-6 material, based on (a) the general swelling model of (3) and (4) and (b) the general swelling model of (8) and (9)

\section{STATISTICAL EVALUATION}

Elaboration of the statistical applicability of the regression equations (i.e., the swelling models) discussed above was conducted with the aid of a statistical analysis of residuals; i.e., measured minus computed vertical swelling. This analysis checks whether the residuals behave as required by the model hypothesis, especially if they are independent, homoscedastic and normally distributed with zero expectation.

This section deals with the aforementioned analysis for the best swelling model as described by (3) and (4) or by (8) and (9). For a check of homoscedasticity, Figure 11 depicts the plot of residual versus computed vertical swelling from these equations for the 897 undisturbed specimens. This figure reveals the following deficiencies: (a) variability of residuals increases with increased predicted vertical swelling; (b) a systematic bias for low predicted vertical swelling.

In addition, for a check of normality, Figure 12 depicts a plot of the cumulative probability distribution of residuals with the theoretical normal distribution function. The figure reveals that the shape of the frequency curve resembles a normal distribution with zero mean. If this is true, the validity of the normality assumption of the residuals is confirmed for both swelling models, (3) and (4) and (8) and (9). To confirm this two-curve resemblance, the Kolmogorov-Smirnov test can be used to check the normality of residuals [8]. 


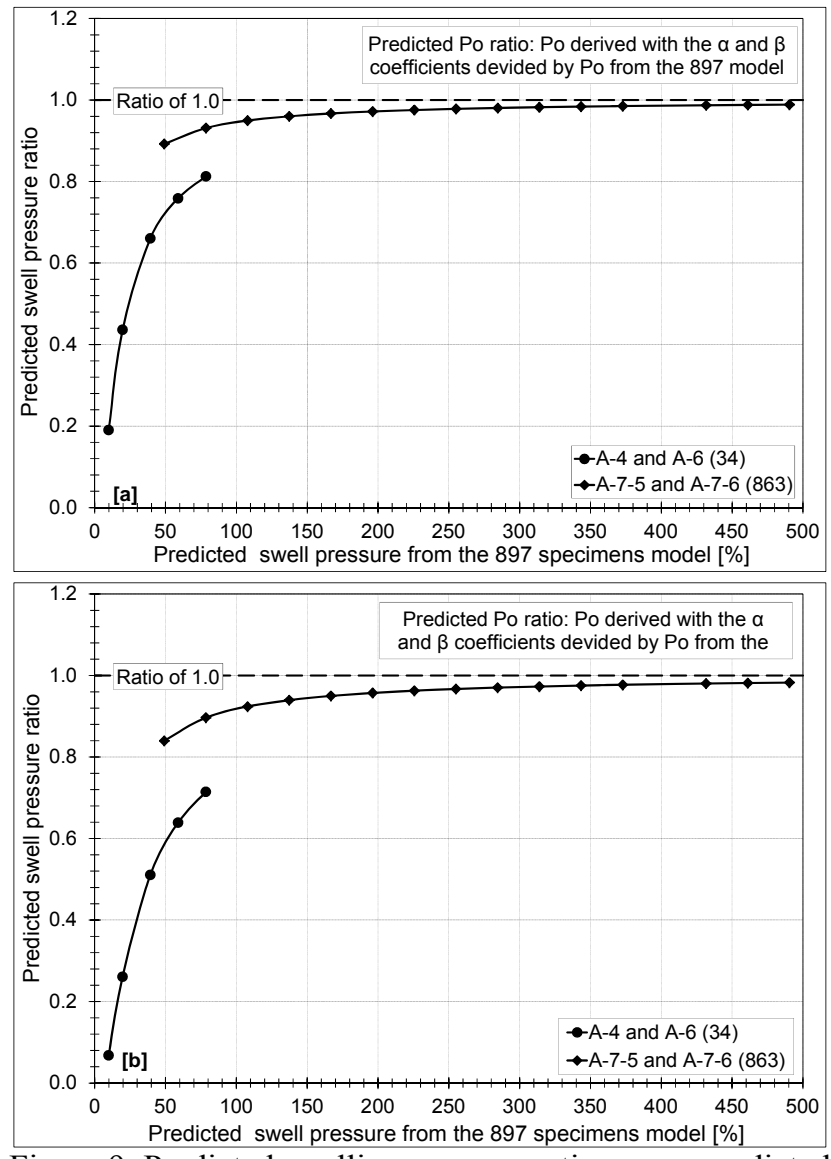

Figure 9: Predicted swelling pressure ratio versus predicted swelling pressure from the general swelling model, with (a) $\log (\mathrm{LL})$ and $\mathrm{D}$ variables and $(\mathrm{b}) \log (\mathrm{PI})$ and $\mathrm{DR}$ variables
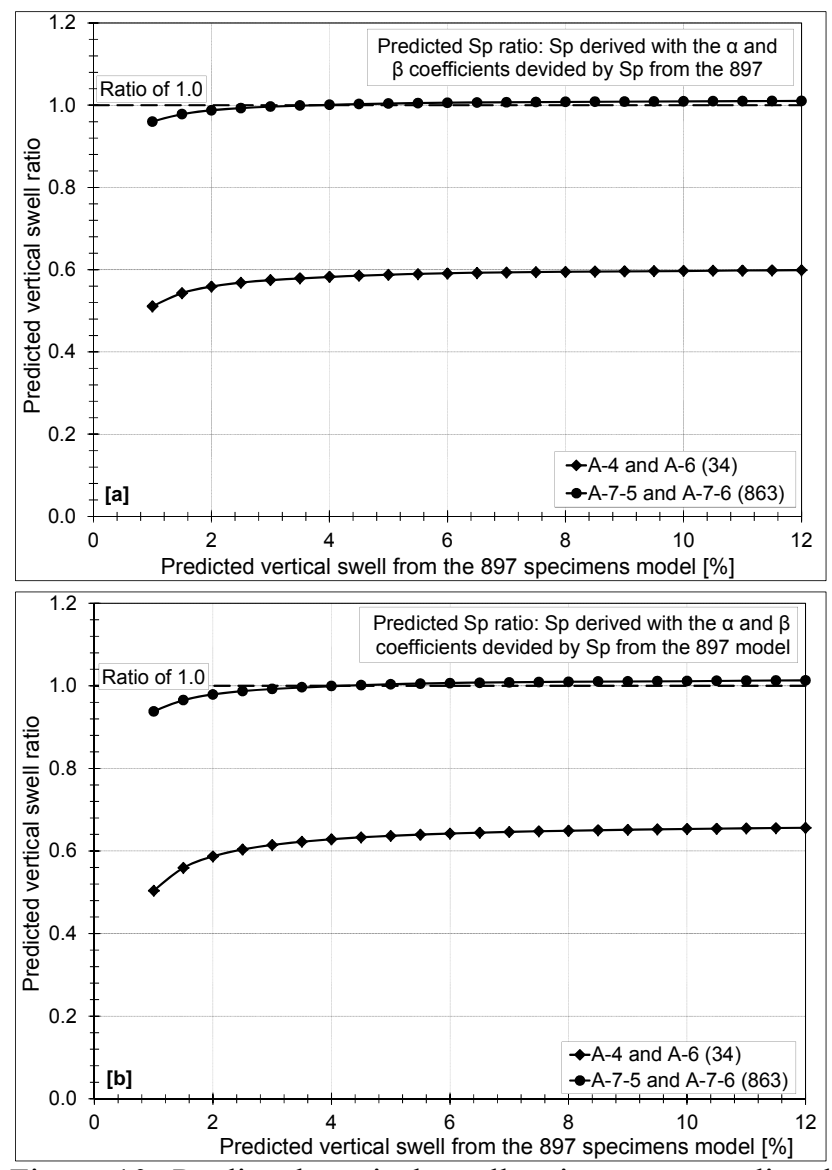

Figure 10: Predicted vertical swell ratio versus predicted vertical swell from the general swell model with (a) $\log (\mathrm{LL})$ and $\mathrm{D}$ variables and (b) $\log (\mathrm{PI})$ and $\mathrm{DR}$ variables
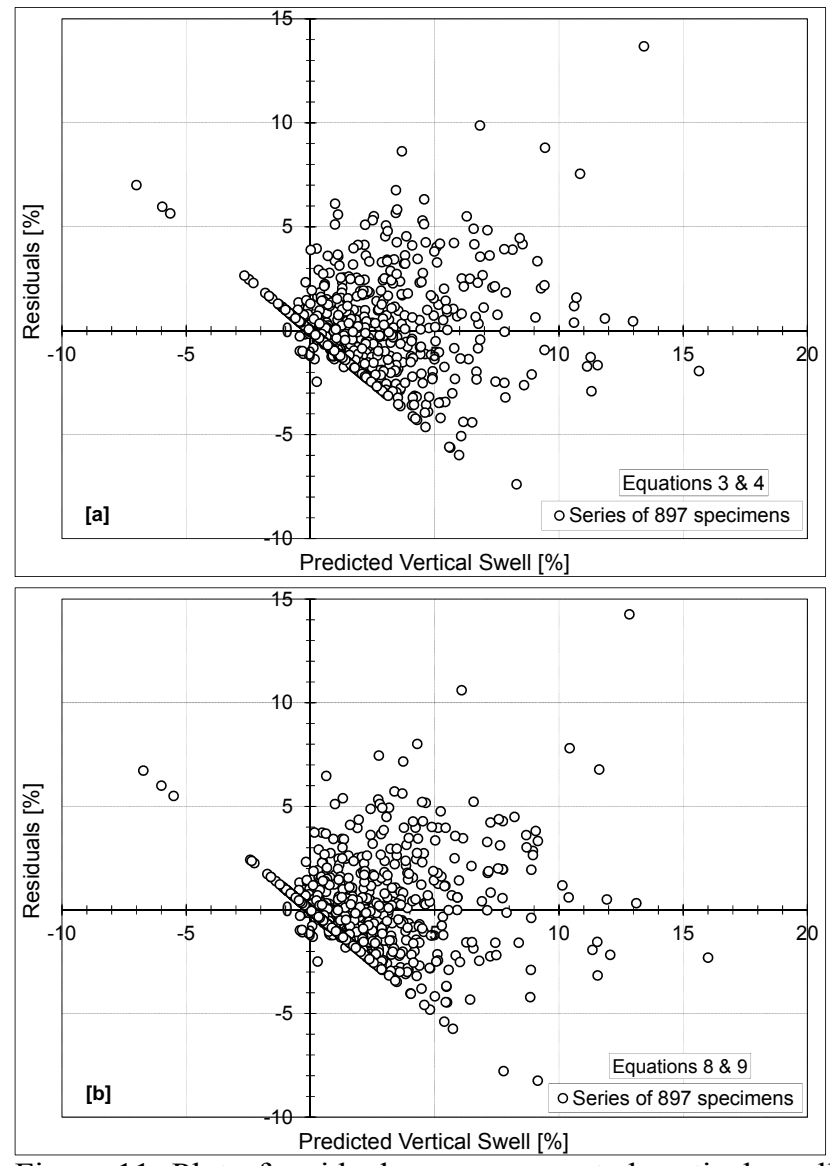

Figure 11: Plot of residual versus computed vertical swell for the 897 undisturbed specimens with utilization of (a) (3) and (4) and (b) (8) and (9)
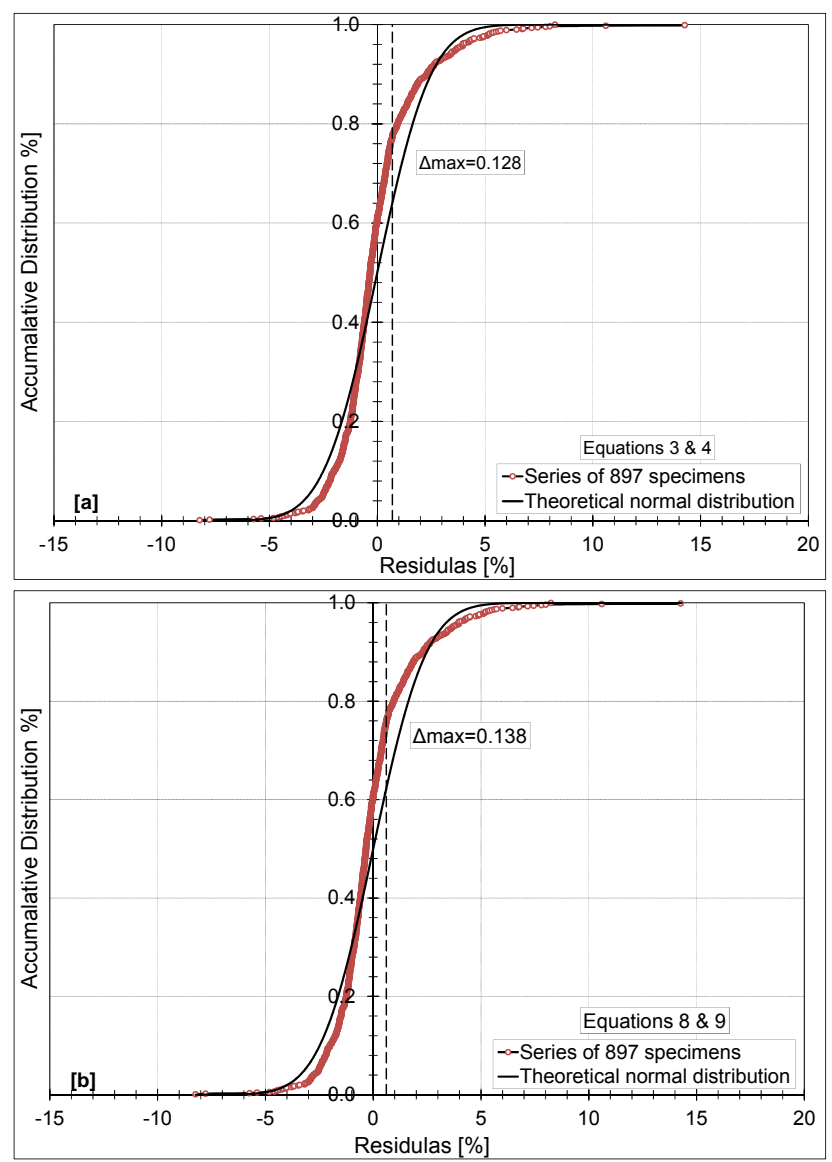

Figure 12: Cumulative probability distribution of residuals plotted against the theoretical normal distribution function values, utilizing (a) (3) and (4) and (b) (8) and (9) 
To recall, the utilization of the Kolmogorov-Smirnov test to check the normality of residuals calls for a determination of the maximum deviation between theoretical line and the sample line on the probability scale. These values are (a) according to Figure 12a, 0.128 for the swelling model of (3) and (4); and (b) according to Figure 12b, 0.138 for the swelling model of (8) and (9). The critical value of the Kolmogorov-Smirnov test statistic for $\alpha=0.05$ and number of specimens minus number of degrees of freedom, (i.e., $897-5=892)$ is 0.045 . Therefore, the hypothesis that the residuals are normally distributed is rejected at the significance level of $\alpha=0.05$.

As for the specific swelling models for the A-4 and A-6 material as described by (11) and (12) or by (15) and (16), the validity of the above analysis of these equations is limited because of the low number of specimens (only 34). Therefore, the test to determine the Kendall's $\tau$ rank correlation coefficient was applied. This test is also suitable for fewer than 40 specimens [14].

In this test, the basic assumption is that predictive models for Sp should rank clays in the same order as they would be ranked if $\mathrm{Sp}$ values were actually measured in the laboratory. In other words, if the measured vertical swelling of a local clay, say clay A, is higher than the measured vertical swelling of clay B at some given vertical pressure, then ideally the predicted $\mathrm{Sp}$ of clay A would also be greater than the predicted Sp of clay B at the same given vertical pressure. If this is not the case, the predictive models will give incorrect indications of the relative performance of the clays under consideration.

In more detail, Kendall's $\tau$ rank correlation coefficient is a standard statistic for quantifying the degree of correspondence between two rankings. Consider paired lists of measured and predicted $\mathrm{Sp}$ values for $n$ clay-specimens, with the paired items ranked in order of the first list (i.e., measured $\mathrm{Sp}$ ) in order of decreasing magnitude, then the Kendall $\tau$ coefficient for the second list (predicted Sp) is defined as in [9]:

$$
\tau=4 \times \mathrm{Q} /[(\mathrm{n} \times(\mathrm{n}-1)]-1
$$

where, $\mathrm{Q}$ denotes number of items in the second list that are also ranked correctly.

A value for $\tau$ equal to 1 means that the ranking of the two lists is in perfect agreement, a value of -1 means that the rankings are in perfect disagreement (i.e., the second list is ranked in the reverse order of the first), and a value of 0 means that the rankings are completely independent of each other. In other words, increasing positive values of $\tau$ correspond to increasing agreement between the two rankings.

The Kendall $\tau$ coefficient can be computed for the measured versus the predicted $\mathrm{Sp}$ for the A-4 and A-6 material. The database of the material is sorted in terms of decreasing measured $\mathrm{Sp}$, and the agreement of the corresponding ranking in terms of predicted $\mathrm{Sp}$ is determined. Table 4 summarizes the Kendall $\tau$ values for the predicted $\mathrm{Sp}$ values as determined using the various models mentioned above for all of the given 34 test results. Unfortunately, the $\tau$ values, although positive, are very small for all the models. In these calculations, a zero difference is considered to be a neutral ranking.
Table 4 also indicates that there may be some minor benefit in using $\log (\mathrm{PI})$ and DR independent variables for the A-4 and A-6 material, instead of the $\log (\mathrm{LL})$ and $\mathrm{D}$ independent variables.

Table 4: The Kendall $\tau$ coefficients for the data of the designated equations

\begin{tabular}{ccc}
\hline Equations & Variables & $\tau$ \\
\hline (11) and (12) & $\log (\mathrm{LL}), \mathrm{W} / \mathrm{PL}$, & 0.18 \\
(3) and (4) with $\alpha$ and $\beta$ & $\mathrm{D}$ & 0.17 \\
\hline (15) and (16) & $\log (\mathrm{PI}), \mathrm{W} / \mathrm{PL}$, & 0.29 \\
(8) and (9) with $\alpha$ and $\beta$ & $\mathrm{DR}$ & 0.25 \\
\hline
\end{tabular}

To sum up, all three residual analyses described in this section indicate that the results that were intended to confirm the basic assumptions laid down in the regression analyses are only of a fare to poor nature. It is suggested, therefore, that in further studies more clay variables be added into the regression equations as suggested in [10] following [13].

\section{CONCLUSIONS}

The statistical analyses performed in this paper to find the best swelling model for the local 897 undisturbed clayey specimens revealed the following:

- The best general swelling model for the total population is that defined by (8) and (9), which utilize the following independent variables: $\log (\mathrm{PI}), \mathrm{W} / \mathrm{PL}$ and DR.

- The second best general swelling model for the total population is that defined by (3) and (4), which utilize the following independent variables: $\log (\mathrm{LL}), \mathrm{W} / \mathrm{PL}$ and D.

- The division of the total population into two groups, A-4 and A-6 material and A-7-5 and A-7-6 material, indicates that the behavior pattern of the first group is entirely different from that of the second group.

- For the A-4 and A-6 material group, the suggestion is to adopt the general swelling model for the total population (i.e., (8) and (9) or alternatively (3) and (4)), with the appropriate values for $\alpha$ and $\beta$ to be inserted into (19) or alternatively (20). Note: These $\alpha$ and $\beta$ values are -0.096 and 0.607 , respectively, for insertion into (19), and -0.166 and 0.670 , respectively, for insertion in (20).

- For the A-7-5 and A-7-6 material group, it is suggested that the general swelling model for the total population (i.e., (8) and (9) or alternatively (3) and (4)) be adopted, since these equations yield almost the same results for this group as does the specific swelling model.

- To increase the accuracy of the prediction process, it is suggested that further studies add more clay variables into the regression equations, such as clay content, mineral clay proportion, mineral clay type and the free swell rate.

Finally, the paper can serve as an appropriate exercise of how existing models can be verified or modified using additional test data information, and how change or modification of 
variables (based on a physical rational) can improve prediction capability (from $\mathrm{R}^{2}=0.457$ to $\mathrm{R}^{2}=0.610$ ).

\section{ACKNOWLEDGMENT}

The paper is based on engineering studies conducted for various Israeli governmental departments and authorities, and thanks are therefore due them.

\section{REFERENCES}

[1] Livneh, M. "Further Developments in the Swelling Model of Expansive Clays under ASTM 4546 and CBR Testing." Proceedings of the First International Conference on Geotechnique, Construction Materials and Environment, Mie, Japan, 2011, pp.257-262.

[2] Livneh, M. "Recent Developments in the Swelling Model of Expansive Clays for Pavement Upheave Calculations." Journal of Testing and Evaluation, JTEVA (ASTM), forthcoming 2012.

[3] Najjar, Y.M., Basheer, I.A., Ali, H.A., and McReynolds, R.L. "Swelling Potential of Kansas Soils, Modeling and Validation Using Artificial Neural Network Reliability Approach." Transportation Research Record 1736, 2000, pp. 141-147.

[4] Seed, H.B., Woodward, R.J., Jr., and Lundgren, R. "Prediction of Swelling Potential for Compacted Clays." Journal of Soil Mechanics and Foundation Division, Vol. 88, No. SM3, ASCE, New York, 1962, pp. 49-51.

[5] Foster, C.R. "Analyses of Road Test Data Using Procedures Developed in the U.S. Army Corps of Engineers Accelerated Traffic Tests." Proceedings of the $1^{\text {st }}$ international Conference on the Structural Design of Asphalt Pavements, University of Michigan, Ann Arbor, 1962, pp. 358-364.

[6] Kassiff, G., Livneh, M., and Wiseman, G. Pavements on Expansive Clays. Jerusalem Academic Press, 1969.

[7] Dongré, R., Leslie, M., D’Angelo, J., Paugh, C., and Gudimettla, J. "Field Evaluation of Witczak and Hirsch Models for Predicting Dynamic Modulus of Hot-Mix.
Asphalt." Journal of the Association of Asphalt Paving Technologists, Vol. 74, 2005, pp. 381-442.

[8] Chong-Yu, X., "Statistical Analysis of Parameters and Residuals of a Conceptual Water Balance Model-Methodology and Case Study", Water Resources Management 15, 2001, pp. 75-92.

[9] Kendall, M., "Rank correlation methods", Charles Griffin and Co., London, 1948.

[10] Livneh, M., and Livneh A.N., "On the Swelling Potential of Remolded Clays Compared with Undisturbed Clays, forthcoming in the Proceedings of the $25^{\text {th }}$ ARRB Conference, Perth, Australia, 2012.

[11] Bandyopadhyay, S.S., "Prediction of Swelling Potential for Natural Soils', Journal of the Geotechnical Engineering Division, ASCE, Vol. 107, No. GT5, 1982, pp 658-661.

[12] Ersin, Y., and Güneş, N., "The Prediction of Swell Percent and Swell Pressure by Using Neural Networks." Mathematical and Computational Application, an International Journal, Vol. 16, No. 2, 2011, pp. 425-436.

[13] U.S. Department of the Army, "Environmental Quality-Environmental Statistics", EM 1110-1-4014, Washington, DC, 2008.

[14] Ersin, Y., "The Use of Neural Networks for the Prediction of Swell Pressure", Geomechnics and Engineering, Vol. 1, No. 1, 2009, pp 75084.

[15] Basma, A.A., "Prediction of Expansion Degree for Natural compacted Clays" Geotech Test Journal, GTJODJ 16(14), 1993, pp.542-549.

International Journal of GEOMATE, June, 2012, Vol. 2, No. 2 (Sl. No. 4), pp. 205-212

MS No.3b received January 19, 2012, and reviewed under GEOMATE publication policies.

Copyright (C) 2012, International Journal of GEOMATE. All rights reserved, including the making of copies unless permission is obtained from the copyright proprietors. Pertinent discussion including authors' closure, if any, will be published in the June 2013 if the discussion is received by Dec. 2012.

Corresponding Author: Moshe Livneh 